\title{
Treatment of Intra- and Extracranial Aneurysms Using the Flow-Redirection Endoluminal Device: Multicenter Experience and Follow-Up Results
}

\author{
(D) F. Drescher, (D). Weber, (D)A. Berlis, (D) S. Rohde, (D)A. Carolus, and (i) S. Fischer
}

\begin{abstract}
BACKGROUND AND PURPOSE: Flow diversion emerged as a crucial treatment option for intracranial aneurysms. We report a multicenter retrospective analysis of the safety and efficacy in the treatment of intracranial aneurysms with the Flow-Redirection Endoluminal Device (FRED) flow diverter, a dual-layer flow-modulation device.
\end{abstract}

\begin{abstract}
MATERIALS AND METHODS: All intracranial aneurysms treated with the FRED between March 2013 and February 2016 at 4 neurovascular centers were included. Angiographic and clinical results were retrospectively analyzed, including all follow-up examinations. Aneurysms were unruptured in 44 cases, whereas 8 treatments were due to an acute SAH from the target aneurysm.

RESULTS: Successful implantation of the FRED was possible in $96.2 \%$ (50/52) of cases. At 3-month follow-up, complete occlusion was determined in $58.1 \%$ (25/43) and near-complete in 25.6\% (11/43). At 12-month follow-up, aneurysm occlusion was complete in 75.0\% (27/36) and near-complete in $22.2 \%$ (8/36). The overall acute and late thromboembolic and hemorrhagic complication rate was $17.3 \%$ (9/52), with a permanent treatment-related morbidity and mortality of $4.0 \%(2 / 50)$ and $2.0 \%(1 / 50)$, respectively, to date.
\end{abstract}

CONCLUSIONS: The FRED device offers an effective tool in the treatment of intracranial aneurysms. The dual-layer design promotes contemporary and stable long-term occlusion rates. Sufficient device expansion should be documented by angiographic CT. Further studies might help to identify a more optimal antiplatelet regimen to avoid thromboembolic complications during the follow-up period.

ABBREVIATIONS: FRED = Flow-Redirection Endoluminal Device; PED = Pipeline Embolization Device

$\mathbf{T}$ he concept of flow diversion has been proved an effective method in the treatment of broad-based, fusiform, and small intracranial aneurysms. ${ }^{1-4}$ The most common flow diverters, such as the Pipeline Embolization Device (PED/PED flex; Covidien, Irvine, California), the Silk/Silk + (Balt Extrusion, Montmorency, France), or the Surpass stent (Stryker Neurovascular, Kalamazoo, Michigan) are single-layer self-expanding devices

Received May 31, 2016; accepted after revision August 16.

From the Knappschaftskrankenhaus Bochum (F.D., W.W., S.F.), Universitätsklinik, Institut für Diagnostische und Interventionelle Radiologie, Neuroradiologie, Nuklearmedizin, Bochum, Germany; Knappschaftskrankenhaus Recklinghausen Klinik für Radiologie Neuroradiologie und Nuklearmedizin (W.W.), Recklinghausen, Germany; Klinikum Augsburg (A.B.), Klinik für Diagnostiche Radiologie und Neuroradiologie, Augsburg, Germany; Klinikum Dortmund (S.R.), Klinik für Radiologie und Neuroradiologie, Dortmund, Germany; and Knappschaftskrankenhaus Bochum (A.C.), Universitätsklinik, Klinik für Neurochirurgie, Bochum, Germany.

Preliminary data from this series was previously presented at: Annual Meeting of the German Society of Neuroradiology, October 15-17, 2015; Cologne, Germany.

Please address correspondence to Sebastian Fischer, MD, Knappschaftskrankenhaus Bochum, Universitätsklinik, Institut für Diagnostische und Interventionelle Radiologie, Neuroradiologie, Nuklearmedizin, In der Schornau 23-25, 44892 Bochum, Germany; e-mail: sebif101@googlemail.com

http://dx.doi.org/10.3174/ajnr.A4964 with low porosity (proportion of metal-free area to total surface area) compared with conventional stents.

In this retrospective study, we analyzed the clinical and angiographic results of 52 intra- and extracranial aneurysms treated with the only available dual-layer flow diverter (Flow-Redirection Endoluminal Device [FRED]; MicroVention, Tustin, California) at 4 neurovascular centers.

\section{MATERIALS AND METHODS \\ Flow-Redirection Endoluminal Device}

The FRED is a braided stent-in-stent device composed of an inner closed-cell stent (48 nitinol wires) with low porosity and an outer mesh with higher porosity ( 16 nitinol wires). The proximal and distal ends of the device are composed of the single-layer mesh of the outer stent, whereas the middle part of the device (80\%) consists of the dual-layer structure. The fluoroscopic visibility results from 4 radiopaque markers at the distal and proximal ends and 2 interwoven helical marker strands delineating the dual-layer section of the device (Fig 1). The FRED is available in 5 nominal diameters $(3.5,4.0,4.5,5.0$, and $5.5 \mathrm{~mm})$ recommended for vessel diameters from 3.0 to $5.5 \mathrm{~mm}$. It is mounted on a microwire with a distal and proximal radiopaque marker. A resheathing of the 
Table 1: Inclusion and exclusion criteria for treatment with FRED

\section{Criteria}

In favor of treatment with FRED
Intradural incidental aneurysm
Intradural or extradural symptomatic aneurysm (mass effect)
Supposed difficulty for coil treatment alone (dome-to-neck ratio of <1.2, broad-based
aneurysm, fusiform morphology, blisterlike shape)
Difficulty or impossibility of neurosurgical clip placement due to aneurysm morphology or
anatomic location
Acutely ruptured aneurysms without any alternative neurosurgical or endovascular
treatment option
Aneurysm remnant or reperfusion after endovascular or microsurgical treatment
Documented response to medicamentous platelet function inhibition
Exclusion for treatment with FRED
Intradural aneurysm with a definable neck
Intradural bifurcation aneurysm
Documented nonresponse to medicamentous platelet function inhibition
Patient preference for alternative treatment options
Patient preference against any treatment

informed of the treatment strategy, including all potential alternatives.

The decision for the endovascular treatment with the FRED resulted from a constantly performed interdisciplinary neurovascular conference at the participating centers. Table 1 summarizes the inclusion and exclusion criteria. On the basis of these criteria, 50 patients ( 40 women, 10 men; mean age, 56 years; range, $20-80$ years) with 52 aneurysms were included. The clinical condition of each patient was measured according to the $\mathrm{mRS}$ before the procedure, at discharge, and after 3 and 12 months. ${ }^{5}$ Thirty patients were asymptomatic before the procedure, 12 patients had an mRS of 1 or 2 caused by the target aneu-

Table 2: Summary of the locations of the treated aneurysms

\begin{tabular}{lcr}
\hline \multicolumn{1}{c}{ Location } & Aneurysms (No.) & Ratio \\
\hline Anterior circulation $(n=39 ; 75.0 \%)$ & & \\
ICA cervical & 8 & $15.4 \%$ \\
ICA cavernous & 3 & $5.8 \%$ \\
ICA paraophthalmic & 21 & $40.5 \%$ \\
ICA Pcom & 3 & $5.8 \%$ \\
ACA & 2 & $3.8 \%$ \\
MCA & 2 & $3.8 \%$ \\
Posterior circulation $(n=13 ; 25.0 \%)$ & & \\
BA & 2 & $3.8 \%$ \\
VA V4 & 9 & $17.3 \%$ \\
PCA & 2 & $3.8 \%$ \\
Total & 52 & $100.0 \%$ \\
\hline
\end{tabular}

Note:-ACA indicates anterior cerebral artery; BA, basilar artery; $\mathrm{VA}$, vertebral artery; PCA, posterior cerebral artery; Pcom, posterior communicating; MCA, middle cerebral artery.

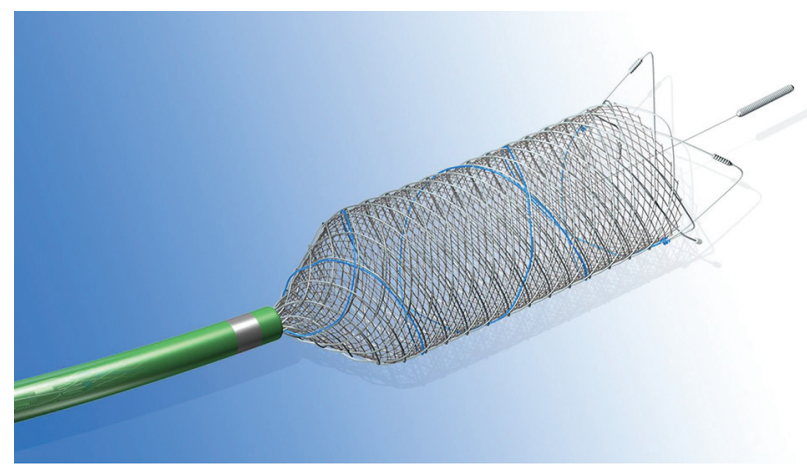

FIG 1. Dual-layer structure of the FRED. The fluoroscopic visibility results from 2 interwoven helical marker strands delineating the dual-layer section (working length) and 4 radiopaque markers at the flared ends.

device is possible as long as $20 \%$ of the device remains unsheathed from the 0.027 -inch microcatheter (point of no return). An undersized device results in an abatement of porosity with a distinct shortening and insufficient coverage of the vessel wall. An oversized device decreases the hemodynamic effect correspondingly.

\section{Selection Criteria, Patient Population, and Clinical Presentation}

This retrospective study was approved by the institutional ethics committee. All patients, apart from those with an acute SAH, were rysm, and 8 patients had an mRS of $>2$ caused by an acute rupture from the aneurysm.

\section{Aneurysm Characteristics, Morphology, and Location}

Of the 52 aneurysms included, 23 were incidental findings, 8 were ruptured (SAH within 5 days before the procedure), and 12 caused symptoms of mass effect. Three were remnants of clipped or wrapped aneurysms, 2 were previously coiled, and 4 were pretreated with other devices (p64; phenox, Bochum, Germany, $n=$ 2; Woven EndoBridge [WEB] aneurysm embolization system; Sequent Medical, Aliso Viejo, California, $n=1$; stent-assisted coiling, $n=1$ ). The series comprises 30 saccular and 21 fusiform aneurysms and 1 blisterlike aneurysm. Forty-four aneurysms were located intradurally compared with 8 extradural locations. Table 2 indicates the locations of the treated aneurysms in detail.

The median fundus size of all saccular aneurysms was $5.0 \mathrm{~mm}$ (range, $2.0-35.0 \mathrm{~mm}$ ) with a median neck width of $4.0 \mathrm{~mm}$ (range, $2.0-20.0 \mathrm{~mm}$ ).

\section{Endovascular Procedure}

All procedures were performed by 5 experienced operators on a biplane DSA unit. A coaxial 8F/6F guiding/intermediate catheter system was navigated into the target artery. The microcatheter was placed distal to the aneurysm at the intended distal landing zone.

Size selection of the flow diverter was based on calibrated measurements of the artery distal and proximal to the aneurysm. The largest diameter of the landing zones was used as a direct reference for the nominal diameter of the device. Once the flow diverter was pushed through the microcatheter to a position appropriate to cover the aneurysm, deployment resulted from a combination of careful retraction of the microcatheter and adjusted backpressure of the delivery wire (push and pull technique). Proper expansion, sufficient apposition to the vessel wall, and the correct position of the device were monitored under continuous fluoroscopy.

If the treatment was combined with coils, a microcatheter was placed initially (jailing). 

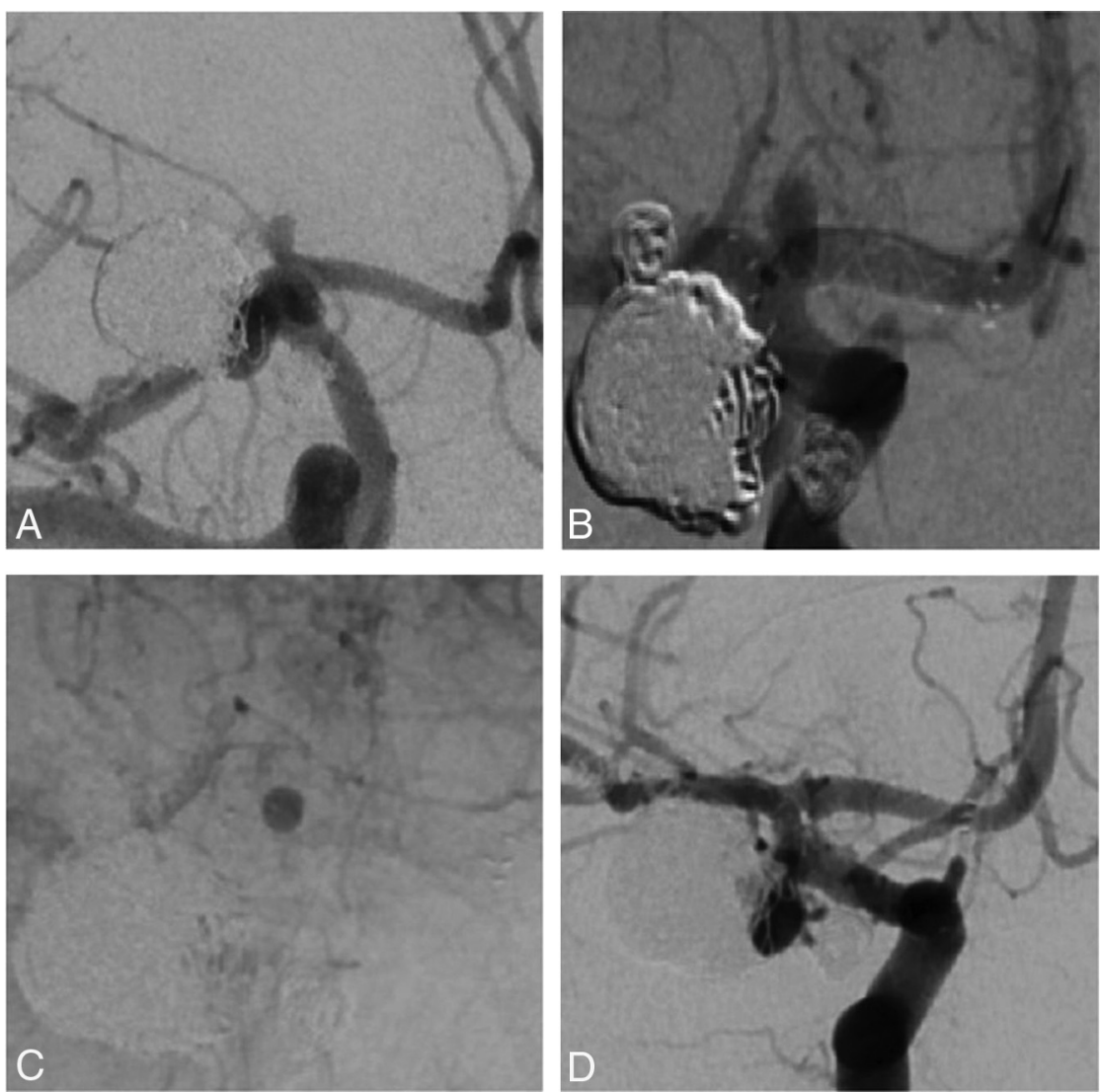

FIG 2. A, A male patient with multiple asymptomatic intracranial aneurysms with a small proximal aneurysm of the $\mathrm{Al}$ segment status post stent-assisted coil occlusion of a distal ICA aneurysm, right oblique and cranial views. B, Placement of a 3.5-/13/7-mm FRED with its flared ends extending toward the ICA bifurcation to cover the aneurysm with the dual-layer part of the device, right oblique and cranial views. C, Stasis of contrast material up to the venous phase, right oblique and cranial views. $D, 4$-month follow-up angiography with complete occlusion of the aneurysm, right oblique and cranial views.

\section{Anticoagulation/Antiplatelet Regimen}

All patients, except for those with ruptured aneurysms, were placed on dual-antiplatelet medication with $100 \mathrm{mg}$ of acetylsalicylic acid and $75 \mathrm{mg}$ of clopidogrel daily at least 5 days before the treatment. Clopidogrel was continued for at least 3 months followed by life-long continuation of acetylsalicylic acid.

The sufficiency was tested by an impedance aggregometry testing method (Multiplate; Roche, Basel, Switzerland). Clopidogrel nonresponders were changed to a loading dose of $180 \mathrm{mg}$ of ticagrelor followed by $90 \mathrm{mg}$ twice daily. The Multiplate test was repeated with rescheduling of the intervention if necessary until a dual-platelet inhibition was clearly ascertained.

Eptifibatide was administered intravenously with a bolus followed by continuous intravenous application for at least 12 hours bridged with a loading dose of $500 \mathrm{mg}$ of acetylsalicylic acid and $300 \mathrm{mg}$ of clopidogrel in ruptured aneurysms. All procedures were performed with the patient under systemic heparinization.

\section{Follow-Up}

Clinical and angiographic follow-up examinations were planned after 3 and 12 months according to the institutional standards. The angiographic results were classified as the following: complete occlusion, minor neck remnant, major residual filling, or unchanged aneurysm filling. The results were independently analyzed by 2 interventional neuroradiologists. ${ }^{6}$

\section{RESULTS \\ Technical and Immediate Angiographic Results}

Overall, 52 cases were included within the sample period (March 2013 to February 2016) at the participating centers. Centers 1 and 3 included 19 cases, whereas 5 cases were included at center 2 , and 9 were from center 4 .

Implantation of the FRED was performed as intended in 50/52 cases (96.2\%) and failed in 2 cases of ICA aneurysms due to a severe elongation of the target vessel. Although placement of the microcatheter distal to the aneurysm was possible without difficulty, a sufficient opening of the flow diverter was not achieved despite several repositioning maneuvers. Both aneurysms were finally treated by stent-assisted coiling.

In 44 cases, a single device was used (Fig 2). Two were coaxially implanted in 2 cases. In 1 case of a large cavernous ICA aneurysm, a single FRED was combined with 3 Silk flow diverters and 5 Pipeline Embolization Devices (case 26). Arguments in favor of $>1$ device included an unchanged aneurysm perfusion after the first device or a large incorporation of the vessel in cases of very wide-neck or fusiform aneurysms.

An incomplete expansion occurred in 4 cases requiring balloon angioplasty. The treatment was combined with coils in 8 cases with the objective of accelerating the process of thrombus formation (Fig 3).

\section{Angiographic Follow-Up Results}

The first follow-up angiography was performed in 41/48 patients with 43/50 aneurysms after a median of 3.0 months (range, 1.0-12.0 months). Of the remaining 7 patients, 2 patients died during the early follow-up period as consequence of their preexisting SAH, 4 patients were lost to follow-up, and 1 patient died due to a delayed aneurysm rupture (case 49). To date, a second follow-up angiography is available for $34 / 48$ patients with $36 / 50$ aneurysms, after a median of 12.0 months (range, 2.0-24.0 months).

The complete occlusion rate improved from $58.1 \%$ (25/43 cases) at the first angiography to $75.0 \%$ (27/36 cases) at the second follow-up examination. A detailed illustration of the results is given in Table 3.

Three cases of asymptomatic moderate-grade in-stent stenosis without hemodynamic relevance were observed during the early follow-up period. Two of these findings remained unchanged during the observational period, whereas the third patient developed an acute in-stent thrombosis 5 months later (case 25). 


\section{Clinical Results and Complications}

Complications were analyzed at discharge and after 3 and 12 months according to their underlying pathomechanism (thromboembolic or hemorrhagic) and their clinical relevance. Asymptomatic complications were those without any worsening on the mRS grading scale; those with an increase on the mRS scale related to the complication were classified as symptomatic. A summary of the complications encountered in this series, including the mortality and morbidity, is given in Tables 4 and 5 .

The overall mortality and morbidity related to the treatment in the entire series is $2.0 \%$ (1/50 patients) and $4.0 \%(2 / 50 \mathrm{pa}-$ tients) to date. The mRS score improved or remained unchanged in $94.0 \%$ (47/50 patients) and worsened in $6.0 \%$ (3/50 patients), related to the treatment.

The overall complication rate most probably related to the treatment was $17.3 \%$ ( $9 / 52$ cases) during
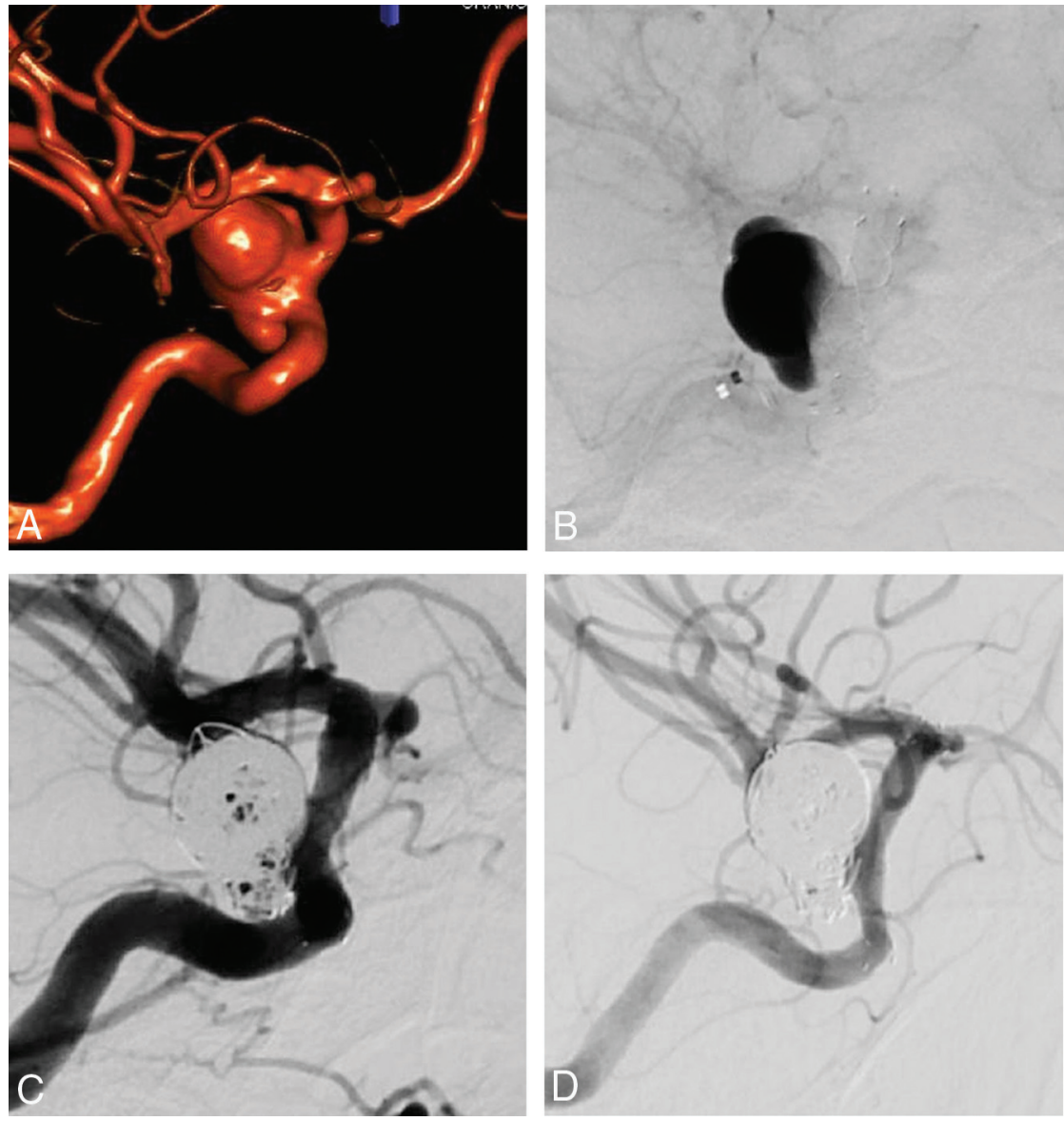

FIG 3. A, Finding of a large irregularly shaped aneurysm of the right ICA (posterior communicating segment) in a woman, causing symptoms of mass effect, 3D rotational angiography. $B$, Placement of a 4.0-/18/12-mm FRED after jailing of a microcatheter. Intra-aneurysmal stasis of contrast material, lateral view. C, Loose coil occlusion of the aneurysm, lateral view. D, Complete occlusion of the aneurysm on 3-month follow-up angiography, lateral view.

Table 3: Occlusion rates at 3- and 12-month follow-up

\begin{tabular}{lcccr}
\hline \multicolumn{1}{c}{ Occlusion } & 3-Month Follow-Up & Ratio & 12-Month Follow-Up & Ratio \\
\hline Complete occlusion & 25 & $58.1 \%$ & 27 & $75.0 \%$ \\
Minor neck remnant & 11 & $25.6 \%$ & 8 & $22.2 \%$ \\
Major residual filling & 3 & $7.0 \%$ & 1 & $2.8 \%$ \\
Unchanged filling & 4 & $9.3 \%$ & 0 & $0.0 \%$ \\
Total & 43 & $100.0 \%$ & 36 & $100.0 \%$ \\
\hline
\end{tabular}
the median follow-up of 12 months; $15.4 \% \quad(8 / 52)$ were thromboembolic compared with $1.9 \%$ (1/52) hemorrhagic complications. Fortunately, only 2 of the thromboembolic complications resulted in a permanent neurologic deterioration (cases 13 and 25). Both were paraophthalmic ICA aneurysms in patients previously placed on ticagrelor due to a nonresponder status to clopidogrel. One patient experienced a parent artery thrombosis 3 weeks after the intervention with ongoing dual-antiplatelet inhibition, whereas the second thrombosis occurred 5 months after cessation of ticagrelor. These 2 patients were discharged with a clinical deterioration to an mRS of 4.

The remaining 6 cases of parent vessel thrombosis remained clinically asymptomatic or caused transient clinical deficits due to a sufficient collateralization via the circle of Willis in 4 and a successful recanalization in the remaining 2 cases (intra-arterial thrombolysis and balloon angioplasty) (Fig 4). These findings were in patients with continued dual-antiplatelet medication except case 25. All were carotid artery aneurysms treated with 1 FRED, except case 26 . This patient was previously treated with 3 Silk and 5 PED flow diverters.

One fatal SAH occurred 19 days after treatment of a large paraophthalmic aneurysm of the ICA with 1 FRED and additional coiling (case 49).

One management-related adverse event without clinical impairment was encountered. This was a mild dissection

Table 4: Summary of complications during the follow-up period

\begin{tabular}{|c|c|c|c|c|c|c|}
\hline Adverse Events & $\begin{array}{l}\text { At Discharge } \\
\text { ( } n=52 \text { cases) }\end{array}$ & Ratio & $\begin{array}{c}\text { 3-Month Follow-Up } \\
\text { ( } n=43 \text { cases) }\end{array}$ & Ratio & $\begin{array}{c}\text { 12-Month Follow-Up } \\
(n=36 \text { cases })\end{array}$ & Ratio \\
\hline Hemorrhagic & 0 & $0.0 \%$ & 1 & $2.3 \%$ & 0 & $0.0 \%$ \\
\hline Thromboembolic, symptomatic & 1 & $1.9 \%$ & 0 & $0.0 \%$ & 1 & $2.8 \%$ \\
\hline Thromboembolic, asymptomatic & 3 & $5.7 \%$ & 2 & $4.7 \%$ & 1 & $2.8 \%$ \\
\hline Total & 4 & $7.6 \%$ & 3 & $7.0 \%$ & 2 & $5.6 \%$ \\
\hline
\end{tabular}


of the V2 segment of the vertebral artery in a female patient with a fusiform aneurysm of the V4 segment, probably caused by a guidewire injury. The intimal disruption was covered with an Enterprise self-expanding stent (Codman \& Shurtleff, Raynham, Massachusetts) without technical difficulty. The patient remained clinically unchanged.

\section{DISCUSSION}

In this retrospective multicenter series, we present the angiographic and clinical results with the FRED in the treatment of 52 extra- and intracranial aneurysms. The series comprises ruptured and unruptured aneurysms of different subgroups (eg, saccular, fusiform, and anterior and posterior circulation). The technical success rate of $96.2 \%$ and the angiographic results with a complete and near-complete occlusion rate of $97.2 \%$ during a median follow-up period of 12.0 months are comparable with or partly superior to those of previously published series concerning flow diversion. ${ }^{1-4,7,8}$

The rate of morbidity and mortality is within the range

Table 5: Morbidity and mortality during the follow-up period

\begin{tabular}{lcccccc}
\hline & $\begin{array}{c}\text { At Discharge } \\
(\boldsymbol{n}=\mathbf{5 0} \text { patients) }\end{array}$ & Ratio & $\begin{array}{c}\text { 3-Month Follow-Up } \\
(\boldsymbol{n}=\mathbf{4 1} \text { patients) }\end{array}$ & $\begin{array}{c}\text { Ratio } \\
\text { 12-Month Follow-Up } \\
(\boldsymbol{n}=\mathbf{3 4} \text { patients) }\end{array}$ & Ratio \\
\hline Morbidity & 1 & $2.0 \%$ & 0 & $0.0 \%$ & 1 & $2.0 \%$ \\
Mortality & 0 & $0.0 \%$ & 1 & $2.0 \%$ & 0 & 0.0 \\
\hline
\end{tabular}

known from previous series. Overall our results demonstrate that FRED is a useful and effective device in the treatment of complex aneurysms. Several technical and clinical aspects require detailed consideration.

\section{Technical Factors of Flow Diversion}

The effectiveness of flow diverters depends on 2 characteristics: the porosity, which is defined as the ratio of the metal-free surface to the total surface area, and the pore density, which describes the number of pores per unit of surface area. ${ }^{9}$ The porosity of the FRED is sectionalized due to its dual-layer design in the middle part, with a comparatively low porosity compared with the proximal and distal overlap of the outer stent. This design offers the possibility of placing maximum coverage above the aneurysm with low coverage at the landing zones to preserve side branches. The hemodynamic impact of this design is similar and probably more effective compared with the available single-layer flow diverters.

The flow-diverting effect can be increased by the implantation of multiple flow diverters in a telescoping manner. The initial implantation of $>1$ device will increase the risk of complications, especially with regard to side branch occlusions and an extended procedure time. ${ }^{10}$ Our angiographic results
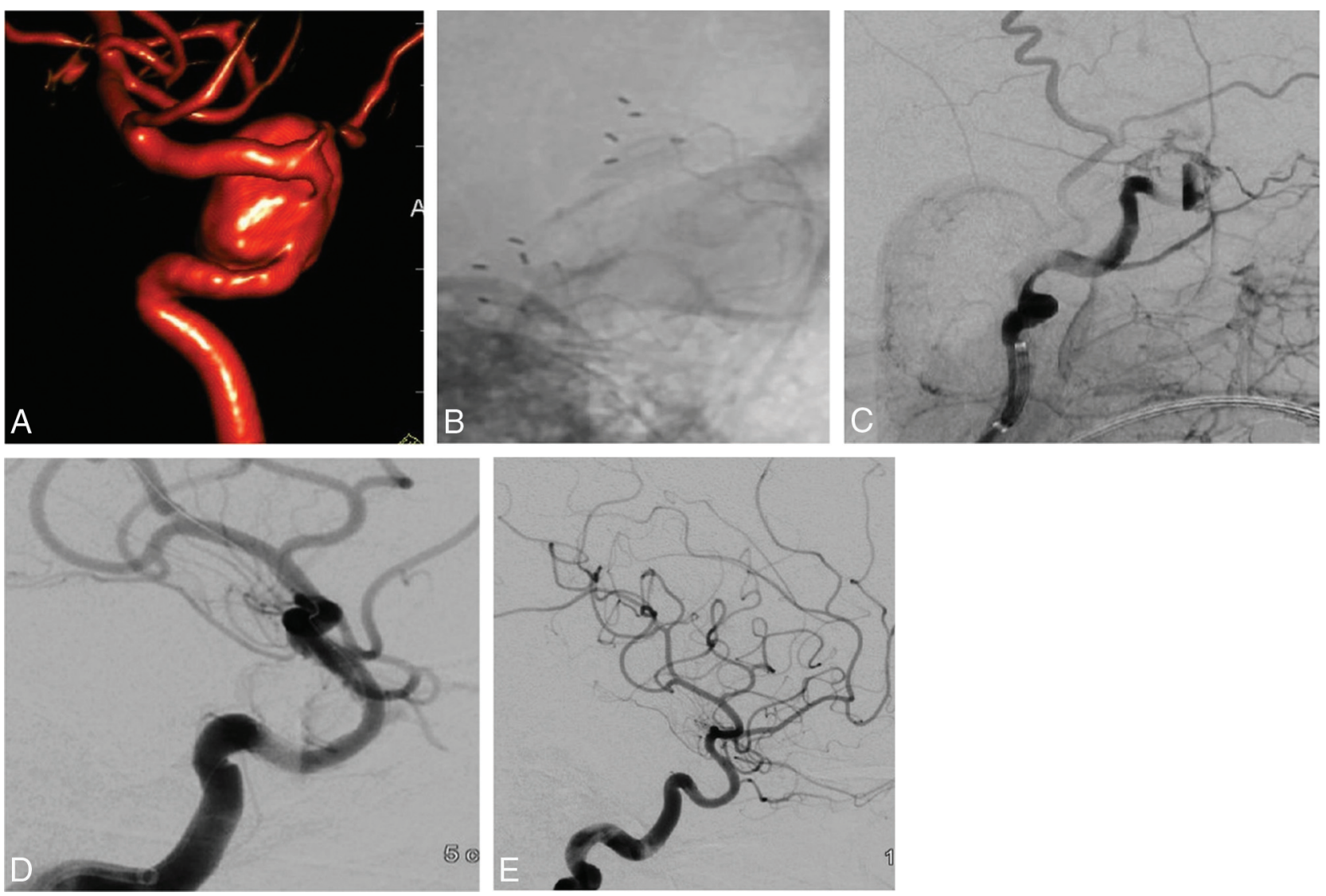

FIG 4. $A$, Incidental finding of a cavernous ICA aneurysm in a female patient, 3D rotational angiography. $B$, Placement of a 3.5-/22/16-mm FRED with incomplete expansion in the midsection of the flow diverter, recorded with fluoroscopy. C, Acute thrombotic occlusion of the ICA caused by the incompletely expanded flow diverter, right anterior oblique view. $D$, Status post dilation of the FRED with a coronary percutaneous transarterial angioplasty balloon (Sequent Medical, $2.75 \times 10 \mathrm{~mm}$ ), right anterior oblique view. E, 3-month follow-up angiography demonstrates complete occlusion of the cavernous aneurysm with regular opacification of the ICA, lateral view. 
Table 6: Complication rates with different flow diverters including the period under review

\begin{tabular}{|c|c|c|c|c|c|c|}
\hline Author & Year & $\begin{array}{c}\text { Flow } \\
\text { Diverter }\end{array}$ & No. of Patients & $\begin{array}{c}\text { Thromboembolic } \\
\text { Complications }\end{array}$ & $\begin{array}{l}\text { Hemorrhagic } \\
\text { Complications }\end{array}$ & $\begin{array}{c}\text { Median Follow-Up } \\
\text { Time (mo) }\end{array}$ \\
\hline Möhlenbruch et al ${ }^{8}$ & 2015 & FRED & 29 & $14.0 \%$ & $3.0 \%$ & 6 \\
\hline Poncyljusz et al ${ }^{11}$ & 2013 & FRED & 6 & $17.0 \%$ & $0.0 \%$ & 3 \\
\hline Briganti et $\mathrm{al}^{12}$ & 2016 & FRED & 20 & $0.0 \%$ & $0.0 \%$ & 12 \\
\hline Lubicz et $\mathrm{al}^{13}$ & 2015 & Silk & 26 & $23.1 \%$ & $11.5 \%$ & 6 \\
\hline Briganti et $\mathrm{al}^{4}$ & 2012 & Silk + Pipeline & 273 & $4.8 \%$ & $5.5 \%$ & 3 \\
\hline Colby et $\mathrm{al}^{7}$ & 2016 & Pipeline Flex & 44 & $2.0 \%$ & $0.0 \%$ & Not applicable \\
\hline De Vries et al $^{14}$ & 2013 & Surpass & 37 & $13.5 \%$ & $5.4 \%$ & 12 \\
\hline Fischer et $\mathrm{al}^{15}$ & 2015 & p64 & 130 & $3.0 \%$ & $0.0 \%$ & 9 \\
\hline Our data & 2016 & FRED & 48 & $15.4 \%$ & $1.9 \%$ & 12 \\
\hline
\end{tabular}

underline the efficiency of a single FRED. A further advantage of the dual-layer design apart from the potential improvement of flow diversion might be found in a strengthened radial force. The radial force vectors of the outer stent might lead to a higher safety of opening, especially when using long devices.

\section{Thromboembolic Complications}

Thromboembolic complications play an important role in the context of flow diversion. Table 6 gives a summary of thromboembolic and hemorrhagic complication rates in preexisting series with flow diverters, including the period under review. The rate of thromboembolic complications is comparatively high in the present series. The underlying factors are presumably multifactorial because we failed to identify a distinct similarity.

The risk of thrombus formation and parent artery occlusion is higher with suboptimal wall apposition as discussed by Möhlenbruch et $\mathrm{al}^{8}$ in their series of 29 patients with 34 aneurysms treated with the FRED. They observed 2 patients (6.9\%) with in-stent thrombosis and performed an in-stent percutaneous transarterial angioplasty of the flow diverter in 17\% (5/29) of their aneurysms exclusively located at the sharp angulation of the carotid siphon. They stressed the importance of a slow and well-controlled pushand-pull technique with the microcatheter held in the central position of the vessel to achieve an optimal opening and apposition of the flow diverter to the vessel wall. They recommended resheathing the flow diverter if the slightest suspicion of incomplete wall apposition occurs.

Buyukkaya et al, ${ }^{16}$ in their series of 34 aneurysms treated with the Silk flow diverter, observed a thromboembolic complication rate of $12.1 \%$. They discussed the difficulty of deployment as indirectly associated with thromboembolic events. A successful deployment is clearly dependent on the personal experience of the interventionalist and becomes more complex in highly curved anatomies such as the carotid siphon. Most interesting, the rate of aneurysms located at the paraophthalmic highly curved segment of the ICA was comparatively high in their series (58.8\%), which was rather similar in our series (40.5\%). This might be a possible explanation for the thromboembolic complications in our series because a suboptimal expansion is more likely in tortuous vessels. This context is underlined by the illustrative case given (Fig 4), which documents an incomplete expansion of the FRED in the curved anatomy of the ICA, which resulted in an immediate instent thrombosis.

In some cases, fluoroscopy alone is inappropriate for proving the sufficient expansion of flow-modulation devices. Advanced techniques such as rotational angiography without subtraction and angiographic CT are helpful in the final assessment after implantation of flow diverters. On the basis of our results, we decided to include angiographic CT (DynaCT; Siemens, Erlangen, Germany) in our routine institutional standard to detect minor device malpositions and irregular expansions. ${ }^{17}$

A further source of thromboembolic complications might be found in the duration and monitoring of the antiplatelet medication. Several studies showed a significant individual variation in the response to clopidogrel. ${ }^{18,19}$ Patients with high platelet reactivity despite clopidogrel treatment are exposed to a higher risk of thromboembolic events. ${ }^{20}$ Factors influencing the responsiveness to clopidogrel and acetylsalicylic acid, such as drug interactions, bioaviability, diabetes, smoking, age, and drug compliance, are clearly identified in the literature. ${ }^{21}$ These conditions are inconsistent among patients and change during the follow-up interval.

Routine platelet function testing during the follow-up interval with a precise analysis of the relevant concomitant circumstances might help to identify patients with a de novo resistance to their antiplatelet therapy. The therapy should be tailored and individualized to those findings by a dose modification or changeover to another P2Y12 antagonist as suggested by Oran et al. ${ }^{22}$

The optimal duration of dual-antiplatelet medication after flow-diverter treatment is still controversial. A continuation of the dual-antiplatelet medication during the process of neoendothelialization up to 12 months might help to decrease the incidence of late thromboembolic events. In the series of Kocer et $\mathrm{al}^{23}$ with 37 aneurysms treated with the FRED, the dual antiplatelet medication was used for at least 6 months, and in cases of in-stent stenosis, the medication was maintained.

The standard duration of dual-antiplatelet medication was comparatively short in our series (3 months), which might serve as an explanation for the delayed thromboembolic complications. However, only 1 thromboembolic complication occurred with acetylsalicylic acid alone.

As described above, our retrospective study protocol did not include platelet-activation testing during the follow-up period, resulting in a failure to identify patients with a recent nonresponder status. This could explain the occurrence of thromboembolic complications in patients believed to be on sufficient dual-antiplatelet therapy. We plan to modify our institutional follow-up standards accordingly. 


\section{Hemorrhagic Complications}

As described above, 1 delayed rupture of a large ICA aneurysm occurred in this series. Several studies identified larger aneurysms as being more prone to delayed aneurysm ruptures. ${ }^{24,25}$ An inflammatory reaction by lytic enzymes such as metalloproteinases might promote degradation of the aneurysmal wall during thrombus formation. Potential strategies to minimize the risk of delayed aneurysm ruptures after flow diversion might aim for an acceleration of intra-aneurysmal thrombus formation and an attenuation of the inflammatory reaction. A combination with additional coiling in large aneurysms might accelerate the process of thrombus formation, though delayed ruptures are reported in cases with additional coiling. ${ }^{4,26,27}$ The positive effect of a concomitant anti-inflammatory medication on the stability of the aneurysmal wall remains unproven. Thielen et $\mathrm{al}^{28}$ could not prove a significant change in the level of lytic enzymes such as metalloproteinase induced by cyclosporine. However, the basic approach of an inflammatory modulation possibly managed with cortisone appears promising and deserves further investigation.

\section{Limitations}

Our study has several limitations. The retrospective analysis of the data might cause inhomogeneity because the standards differ slightly among the centers. However, all cases were performed according to a consistent study protocol.

Further limitations are the wide range of different aneurysm types (ruptured, fusiform, saccular, and blister) included in this series and the lack of comparability with conventional treatment strategies. The entire cohort is too small for a significant analysis of the safety and efficacy of the different subtypes of aneurysms treated with the FRED.

Regarding the late thromboembolic events in this series, an analysis of the dual-antiplatelet response during the follow-up period would have been of major interest to identify the proportion of subjects resistant to dual antiplatelet medication and to verify the individual compliance.

Nevertheless, to the best of our knowledge, this is the largest series of aneurysms treated with the FRED comprising a longterm follow-up evaluation of the angiographic and clinical course.

\section{CONCLUSIONS}

The technical and angiographic success rate with the FRED is compelling. Contemporary aneurysm occlusion can be accomplished with a single device in most cases. The dual-layer design promotes contemporary and stable occlusion rates. Exact sizing of the device with a consistent expansion and a sufficient wall apposition ideally documented with angiographic CT and rotational angiography without subtraction are essential factors in the management of aneurysms treated with FRED.

Routine platelet-activation testing during the follow-up period might help to decrease the incidence of late thromboembolic events. Further prospective studies may evaluate the implementation of an idealized, individually tailored long-term antiplatelet strategy.

Disclosures: Werner Weber-RELATED: Other: proctor for MicroVention Terumo. Ansgar Berlis-RELATED: Consulting Fee or Honorarium: MicroVention/Terumo, Comments: proctor; Support for Travel to Meetings for the Study or Other Pur- poses: MicroVention/Terumo, Comments: invited lectures at meetings, arranged by MicroVention/Terumo; UNRELATED: Consultancy: Sequent Medical, Covidien, Stryker; Comments: proctor contract; Payment for Lectures including Service on Speakers Bureaus: Sequent Medical, Covidien, Stryker, Penumbra; Comments: invited lectures at meetings, arranged by MicroVention/Terumo. Stefan Rohde-UNRELATED: Payment for Lectures including Service on Speakers Bureaus: $<€ 1000$, MicroVention, ev3; Travel/Accommodations/Meeting Expenses Unrelated to Activities Listed: $<€ 1000$, MicroVention, Stryker Neurovascular. Sebastian Fischer-UNRELATED: Board Membership: advisory board member for Codman Neurovascular.

\section{REFERENCES}

1. Fischer S, Vajda Z, Aguilar Perez M, et al. Pipeline embolization device (PED) for neurovascular reconstruction: initial experience in the treatment of 101 intracranial aneurysms and dissections. Neuroradiology 2012;54:369-82 CrossRef Medline

2. Brinjikji W, Murad MH, Lanzino G, et al. Endovascular treatment of intracranial aneurysms with flow diverters: a meta-analysis. Stroke 2013;44:442-47 CrossRef Medline

3. D'Urso PI, Lanzino G, Cloft HJ, et al. Flow diversion for intracranial aneurysms: a review. Stroke 2011;42:2363-68 CrossRef Medline

4. Briganti F, Napoli M, Tortora F, et al. Italian multicenter experience with flow-diverter devices for intracranial unruptured aneurysm treatment with periprocedural complications: a retrospective data analysis. Neuroradiology 2012;54:1145-52 CrossRef Medline

5. Rankin J. Cerebral vascular accidents in patients over the age of 60 , II: prognosis. Scott Med J 1957;2:254-68 Medline

6. Joshi MD, O'Kelly CJ, Krings $\mathrm{T}$, et al. Observer variability of an angiographic grading scale used for the assessment of intracranial aneurysms treated with flow-diverting stents. AJNR Am J Neuroradiol 2013;34:1589-92 CrossRef Medline

7. Colby GP, Lin LM, Caplan JM, et al. Immediate procedural outcomes in 44 consecutive Pipeline Flex cases: the first North American single-center series. J Neurointerv Surg 2016;8:702-09 CrossRef Medline

8. Möhlenbruch M, Herweh C, Jestaedt L, et al. The FRED flow-diverter stent for intracranial aneurysms: clinical study to assess safety and efficacy. AJNR Am J Neuroradiol 2015;36:1155-61 CrossRef Medline

9. Sadasivan C, Cesar L, Seong J, et al. An original flow diversion device for the treatment of intracranial aneurysms: evaluation in the rabbit elastase-induced model. Stroke 2009;40:952-58 CrossRef Medline

10. Tan LA, Keigher KM, Munich SA, et al. Thromboembolic complications with Pipeline Embolization Device placement: impact of procedure time, number of stents and pre-procedure P2Y12 reaction unit (PRU) value. J NeuroIntervent Surg 2015;7:217-21 CrossRef Medline

11. Poncyljusz W, Sagan L, Safranow, et al. Initial experience with implantation of a novel dual layer-flow diverter FRED. Wideochir Inne Tech Maloinwazyjne 2013;8:258-64 CrossRef Medline

12. Briganti F, Leone G, Ugga G, et al. Safety and efficacy of flow redirection endoluminal device (FRED) in the treatment of cerebral aneurysms: a single center experience. Acta Neurochir 2016;158: 1745-55 CrossRef Medline

13. Lubicz B, Van der Elst O, Collignon L, et al. Silk flow-diverter stent for the treatment of intracranial aneurysms: a series of 58 patients with emphasis on long-term results. AJNR Am J Neuroradiol 2015; 36:542-46 CrossRef Medline

14. De Vries J, Boogarts J, Van Norden A, et al. New generation of flow diverter (Surpass) for unruptured intracranial aneurysms: a prospective single-center study in 37 patients. Stroke 2013;44:1567-77 CrossRef Medline

15. Fischer S, Aguilar-Pérez M, Henkes E, et al. Initial experience with p64: a novel mechanically detachable flow diverter for the treatment of intracranial saccular sidewall aneurysms. AJNR Am J Neuroradiol 2015;36:2082-89 CrossRef Medline

16. Buyukkaya R, Kocaeli H, Yildirim N, et al. Treatment of complex intracranial aneurysms using flow diverting Silk ${ }^{\circledR}$ stents: an analy- 
sis of 32 consecutive patients. Interv Neuroradiol 2014;20:729-35 CrossRef Medline

17. Faragò G, Caldiera V, Tempra G, et al. Advanced digital subtraction angiography and MR fusion imaging protocol applied to accurate placement of flow diverter device. J NeuroInterv Surg 2016;8:e5 CrossRef Medline

18. Gurbel PA, Bliden KP, Hiatt BL, et al. Clopidogrel for coronary stenting: response variability, drug resistance, and the effect of pretreatment platelet reactivity. Circulation 2003;107:2908-13 CrossRef Medline

19. Petricevic M, Milicic D, White A, et al. Development of a concept for a personalized approach in the perioperative antiplatelet therapy administration/discontinuation management based on multiple electrode aggregometry in patients undergoing coronary artery surgery. J Thromb Thrombolysis 2015;40:383-91 CrossRef Medline

20. Fifi JT, Brockington C, Narang J, et al. Clopidogrel resistance is associated with thromboembolic complications in patients undergoing neurovascular stenting. AJNR Am J Neuroradiol 2013;34:716-20 CrossRef Medline

21. Nakagawa I, Park HS, Yokoyama S, et al. Influence of diabetes mellitus and cigarette smoking on the variability of the clopidogrelinduced antiplatelet effect and efficacy of active management of the target $\mathrm{P} 2 \mathrm{Y} 12$ reaction unit range in patients undergoing neurointerventional procedures. J Stroke Cerebrovasc Dis 2016;25:163-71 CrossRef Medline

22. Oran I, Cinar C, Bozkaya H, et al. Tailoring platelet inhibition according to multiple electrode aggregometry decreases the rate of thromboembolic complications after intracranial flow-diverting stent implantation. J NeuroIntervent Surg 2015;7:357-62 CrossRef Medline

23. Kocer N, Islak C, Kizilkilic O, et al. Flow Re-direction Endoluminal Device in treatment of cerebral aneurysms: initial experience with short-term follow-up results. J Neurosurg 2014;120:1158-71 CrossRef Medline

24. Rouchaud A, Brinjikji W, Lanzino G, et al. Delayed hemorrhagic complications after flow diversion for intracranial aneurysms: a literature overview. Neuroradiology 2016;58:171-77 CrossRef Medline

25. Kulcsár Z, Houdart E, Bonafé $A$, et al. Intra-aneurysmal thrombosis as a possible cause of delayed aneurysm rupture after flow-diversion treatment. AJNR Am J Neuroradiol 2011;32:20-25 CrossRef Medline

26. Kallmes DF, Hanel R, Lopes D, et al. International retrospective study of the Pipeline Embolization Device: a multicenter aneurysm treatment study. AJNR Am J Neuroradiol 2015;36:108-15 CrossRef Medline

27. Turowski B, Macht S, Kulcsar Z, et al. Early fatal hemorrhage after endovascular cerebral aneurysm treatment with a flow diverter (SILK-Stent): do we need to rethink our concepts? Neuroradiology 2011;53:37-41 CrossRef Medline

28. Thielen E, McClure M, Rauchaud A, et al. Concomitant coiling reduces metalloproteinase levels in flow-diverter treated aneurysms but anti-inflammatory treatment has no effect. $J$ Neurointervent Surg 2016 Mar 14. [Epub ahead of print] Medline 